\title{
Brasilidade, heroísmo, utilidade e necessidade: a construção de um ethos pela propaganda institucional da Petrobras ${ }^{1}$
}

\section{Brazilianness, heroism, utility, and necessity:} the built of an ethos by Petrobras's institutional advertisement

Brasilidad, heroísmo, utilidad y necesidad: la construcción de un ethos por la propaganda institucional de Petrobras

Magno Vieira da Silva

- Doutorando em Ciências da Comunicação pela Escola de Comunicações e Artes da Universidade de São Paulo (ECA-USP)

- Mestre em Comunicação e Informação pela Universidade Federal do Rio Grande do Sul (UFRGS)

- Bacharel em Comunicação Social com habilitação em Relações Públicas pela ECA/USP

- Pesquisador do Grupo de Pesquisa em Comunicação Organizacional, Cultura e Relações de Poder (GCCOP) da UFRGS

- E-mail: vieira.magno@gmail.com

\section{Rudimar Baldissera}

- Doutor em Comunicação Social pela Pontifícia Universidade Católica do Rio Grande do Sul (PU/CRS).

- Professor associado do Departamento de Comunicação da Faculdade de Biblioteconomia e Comunicação da Universidade Federal do Rio Grande do Sul (UFRGS)

- Professor, pesquisador e coordenador do Programa de Pós-Graduação em Comunicação e Informação (PPGCOM) da UFRGS

- $\quad$ Líder do Grupo de Pesquisa em Comunicação Organizacional, Cultura e Relações de Poder (GCCOP) da UFRGS

- E-mail: rudimar.baldissera@ufrgs.br 


\section{Resumo}

Neste trabalho, estuda-se a organização Petróleo Brasileiro S.A. (Petrobras) considerando-se a existência de atributos simbólicos reconhecidos e utilizados por sua comunicação organizacional. A partir da noção de ethos discursivo, empregada como tópico analítico, estudam-se quatro propagandas institucionais da empresa, em que se busca verificar as estratégias discursivas utilizadas para atualizar e (re)afirmar os atributos de brasilidade, heroísmo, utilidade e necessidade que envolvem a organização.

\section{PALAVRAS-CHAVE: COMUNICAÇÃO ORGANIZACIONAL・ETHOSDISCURSIVO • PROPAGANDA INSTITUCIONAL・PETROBRAS.}

\section{Abstract}

In this article, Petróleo Brasileiro S.A. (Petrobras) organization is studied considering the existence of symbolic attributes recognized and used by its organizational communication. Based on the concept of discursive ethos, applied as an analytical topic, four institutional advertisements of this company are studied to verify which discursive strategies are used to update and (re)affirm the attributes of "Brazilianness", heroism, utility and necessity that surround the organization.

KEYWORDS: ORGANIZATIONAL COMMUNICATION • DISCOURSIVE ETHOS•INSTITUTIONAL ADVERTISING • PETROBRAS.

\section{Resumen}

En este trabajo se estudia la organización Petróleo Brasileiro S./A. - Petrobras teniendo en cuenta la existencia de atributos simbólicos reconocidos y utilizados por su comunicación organizacional. A partir de la noción de ethos discursivo, utilizado como tópico de análisis, se estudian cuatro anuncios de publicidad institucional de la empresa, y se busca verificar las estrategias discursivas utilizadas para actualizar y (re) afirmar los atributos de brasilidad, heroísmo, utilidad y necesidad relacionados con la organización. 


\section{SOBRE O ESTUDO}

As organizações apresentam-se e são (re)apresentadas pelo acionamento de diferentes elementos de linguagem - articulação de signos verbais, imagéticos, sonoros e de outros sistemas - no intuito de propor determinados sentidos de si mesmas. No âmbito da comunicação organizacional, especialmente na dimensão da "organização comunicada" (Baldissera, 2009a), implementam estratégias discursivas visando qualificação positiva pelos públicos. Nessa direção, oferecem sentidos de si, muitas vezes pela movimentação de signos relativos à identidade organizacional, que acreditam ter mais potencialidade para gerar identificação, adesão e/ou aprovação dos públicos considerados os contextos em que são atualizados. Portanto, pela comunicação - processos e produtos -, a organização seleciona, organiza, circula e dá visibilidade a determinados sentidos de si, conforme suas definições estratégicas.

Sob esse enfoque, neste estudo atenta-se para a comunicação organizacional da Petróleo Brasileiro S.A. (Petrobras). A escolha da organização deveu-se a várias questões, com destaque para o fato de ser uma das organizações de mais relevância no contexto brasileiro, ser alvo e mote de permanentes disputas discursivas nos âmbitos econômico, político e tecnológico, bem como na arena midiática, e fazer amplo uso da comunicação estratégica com simbolismos identitários. Neste artigo, exploram-se dados de campo e alguns dos resultados apresentados por Silva (2012).

Como objeto empírico foram selecionados quatro anúncios impressos (propagandas institucionais), considerando os seguintes critérios: a) ter sido veiculado em revista de grande circulação nacional (visibilidade); b) ser anúncio de propaganda institucional para o público em geral; e c) ter sido produzido e veiculado durante ou logo após uma situação contextual que trouxe algum impacto (perturbações) para a Petrobras - análise do contexto de veiculação (considerando-se, em perspectiva discursiva, que um texto, um anúncio, sempre responde a textos anteriores e prepara textos futuros, essa análise consistiu em pesquisa documental e bibliográfica para compreender o contexto de produção e veiculação de cada anúncio)². Atendidos esses critérios, destaca-se que os anúncios selecionados para a análise foram veiculados no período de 1969 e 2013.

Selecionados os anúncios, e com o objetivo de explicar as estratégias discursivas empregadas pela Petrobras para (re) afirmar alguns dos atributos simbólicos a ela associados em seu processo histórico, empregou-se a noção de ethos discursivo (Maingueneau, 2008) como base analítica. Assim, dos sete simbolismos associados à organização - Petrobras 1) "sinônimo de Brasil"; 2) "heroica"; 3) "empreendedora"; 4) "útil e necessária"; 5) "eficiente"; 6) "moderna e tecnológica"; e 7 ) "responsável" (Silva, 2012) -, esta análise é orientada para os três preponderantes³: Petrobras "sinônimo de Brasil", "heroica" e "útil e necessária".

A seguir, antes da análise propriamente dita, discorre-se, de modo sucinto, sobre alguns dos fundamentos desta pesquisa e apresentam-se os simbolismos associados à Petrobras que orientarão o estudo.

\section{SOBRE COMUNICAÇÃO ORGANIZACIONAL: UMA COMPREENSÃO}

Neste trabalho, compreende-se comunicação organizacional como "processo de construção e disputa de sentidos no âmbito das relações organizacionais" (Baldissera, 2008, p. 169). De natureza relacional, essa compreensão de comunicação organizacional pressupõe a ação dos diferentes sujeitos (individuais e coletivos) que transacionam, disputam, (re)constroem

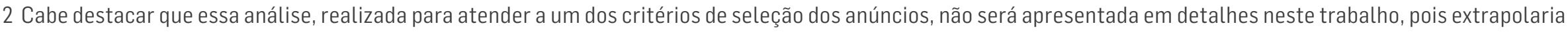
muito as dimensões permitidas para 0 artigo.

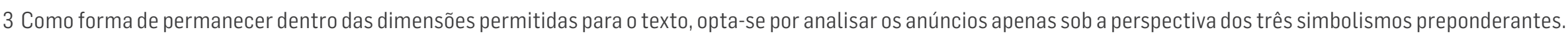


sentidos de mundo e, portanto, da própria organização. Assim, não é isenta, pois que sempre atualiza e materializa intenções, concepções de mundo e relações de poder.

Ao tempo em que é empregada para a (re)construção (e, mesmo, instituição) da cultura e da identidade organizacionais, hologramática e recursivamente (Morin, 2001), também se prende em suas teias - valores, crenças, simbolismos, normas que passam a se exercer sobre ela, orientando-a. Cultura/identidade e a comunicação organizacional conformam relações de interdependência.

Em direção semelhante, atenta-se para o fato de que, conforme Oliveira e Paula (2008), a produção de sentidos se dá pela articulação das diferentes linguagens, e o sentido é essencialmente coletivo. Portanto, tem a relação comunicacional como condição para sua realização e/ou atualização. 0 sentido, segundo as autoras, é construído a partir daquilo que a comunicação organizacional (em sentido complexo) movimenta no âmbito das práticas discursivas articuladas e interdependentes das instâncias de produção, circulação e consumo.

Portanto, as organizações podem ser vistas como agentes discursivos ${ }^{4}$ em processos que se materializam no ambiente organizacional e para além dele, e estão a todo tempo construindo, transacionando, organizando e propondo sentidos para qualificarem sua imagem-conceito ${ }^{5}$ (Baldissera, 2004), instituírem-se como legítimas e ampliarem os ganhos. Nessa direção, é comum o desejo de controlarem as internalizações de sentidos realizadas pelos sujeitos/públicos, bem como as respostas dadas por eles a essas proposições. Assim, tendem a agir em perspectiva de constituição e exibição de um ethos, manifestado discursivamente e sob matizes particulares. 0 ethos discursivo (Maingueneau, 2008), dessa forma, auxilia na conformação das organizações como atores comunicativos.

\section{CONSIDERAÇÕES SOBRE ETHOS DISCURSIVO}

Compreender a comunicação organizacional em sua face discursiva, organizadora, construtora e propositora de sentidos é também observar as diferentes instâncias, níveis e suportes sobre os quais circula o discurso organizacional. Isso exige pensar a comunicação como processo que atualiza as concepções e as falas oficiais; dimensão da "organização comunicada" (Baldissera, 2009a), ou seja, âmbito da fala organizacional autorizada. É, portanto, lugar qualificado para que a organização diga de si, articule seu discurso e se apresente de acordo com demandas contextuais.

Sob esse viés, para as organizações, é pela comunicação organizacional que as escolhas realizadas e as estratégias delineadas são materializadas de modo a atualizar e (re)afirmar o discurso. Observe-se, também, que mesmo quando não há clara intenção e/ou estratégia de comunicação, tudo o que estiver disposto nos materiais da produção discursiva (site institucional, jornal, anúncios etc.) do âmbito da "organização comunicada" será fala oficial e incidirá na conformação discursiva e nos sentidos que oferece de si.

Assim, a forma como a organização se posiciona discursivamente, orientada pelas suas concepções (formações discursivas), diz de como ela se vê e/ou de como deseja ser vista (Baldissera e Silva, 2012). Ao orientar-se discursivamente para oferecer

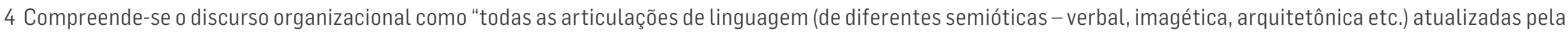
organização, como atividade de sujeitos inscritos em contextos específicos" (Baldissera, 2010, p. 204).

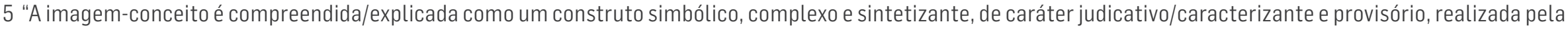

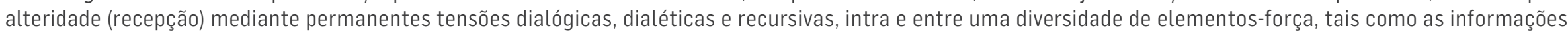

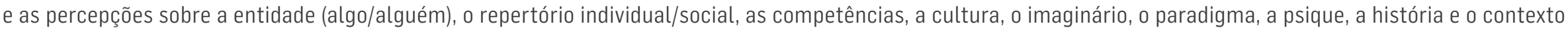
estruturado" (Baldissera, 2004, p. 278). 
imagens de si, a organização age sob a perspectiva de ethos discursivo, que, de acordo com Maingueneau (2008, p. 56), objetiva "causar boa impressão mediante a forma com que se constrói o discurso, em dar uma imagem de si capaz de convencer 0 auditório, ganhando sua confiança". Ainda conforme o autor, o ethos discursivo é o mecanismo que possibilita ao orador tornar-se digno de fé; em última instância, relaciona-se à construção de uma identidade para o orador, com o emprego de estratégias de fala capazes de agradar à audiência.

Por meio do ato de enunciação, o ethos discursivo compreende a construção e a proposta de sentidos que atendem aos desejos de um posicionamento específico da organização-locutora. Maingueneau (2011, p. 72) ressalta que o ethos "possui uma vocalidade específica, que permite relacioná-lo a uma fonte enunciativa, por meio de um tom que indica quem o disse: o termo 'tom' apresenta a vantagem de valer tanto para o escrito quanto para o oral. Pode-se falar do 'tom' de um livro".

Complementarmente, destaca-se que o ethos discursivo, de acordo com o mesmo autor, é parte da "cena de enunciação" (campo de inscrição do discurso e pressuposto para sua enunciação; prescreve algumas das condições sob as quais se dá a construção do ethos). Observa-se que a "cena de enunciação" pode envolver signos que não são verbais (como os imagéticos) para os quais é preciso atentar à luz da noção de ethos.

Como apresentação e ofertas de si, a perspectiva de ethos conforma uma das estratégias expressivas na dimensão da "organização comunicada". Neste estudo o ethosé materializado pela comunicação organizacional na forma de propagandas institucionais da Petrobras.

\section{DOS PROCEDIMENTOS METODOLÓGICOS}

Conforme se destacou, os dados aqui apresentados resultam da articulação de vários procedimentos metodológicos: pesquisa histórica, documental, bibliográfica e de aplicação do tópico de ethos discursivo (Maingueneau, 2008). Estudo exploratório sobre os simbolismos da Petrobras, realizado anteriormente, indicava a existência de um conjunto de fatos históricos, bem demarcados e registrados (dentre outros, em documentos, dissertações e teses), que se exerceram fortemente na sua conformação simbólica. Além disso, analisando-se a história da organização articulada à propaganda institucional, foi possível perceber que os signos que atualizam tal simbolismo foram/são amplamente acionados pela comunicação organizacional na proposição, atualização e (re)afirmação de determinados sentidos junto aos públicos.

Neste ponto, importa destacar que, conforme Silva (2012), uma miríade de fatos históricos influenciou a caracterização da Petrobras como organização permeada por atributos simbólicos que foram/são utilizados por sua comunicação organizacional na proposição, atualização e (re)afirmação de sentidos diante da alteridade (públicos). Silva (2012, p. 96-97) também afirma que o estudo do processo histórico da Petrobras permitiu que fossem identificados elementos que configuraram sete principais simbolismos (atributos simbólicos) associados a ela, conforme se destaca a seguir.

0 primeiro deles compreende a conformação de Petrobras como "sinônimo de Brasil". Esse atributo simbólico fundamenta-se

no nacionalismo expresso pela luta de membros da sociedade e algumas alas de governo pela instauração do monopólio estatal, na polaridade de discussões a seu respeito, e na expressão, por meio da marca BR (talvez a mais importante marca que representa o Brasil no mundo) e de peças de comunicação, das cores identificadas com a nação (verde, amarelo, azul) e da evocação dos sentimentos de brasilidade e de pertencimento. (Silva, 2012, p. 96)

Petrobras "heroica" é o segundo simbolismo, e está diretamente relacionado com a 
história do surgimento da organização e da narração (por ela própria e por terceiros) dos feitos mais marcantes de sua trajetória, sempre em relação com o ambiente sócio-político brasileiro, apresentando-se (e por vezes sendo representada) como "a" grande e intocável organização e, ao mesmo tempo, muito próxima por "ser" dos brasileiros. (Silva, 2012, p. 96)

O terceiro compreende a Petrobras "empreendedora". Isso é, propiciada "pelo fato de a autonomia conquistada pela organização ter lhe dado a legitimidade necessária para ocupar o posto de incentivadora da formação de uma indústria de base - papel que, em princípio, deveria ser do Estado, essencialmente" (Silva, 2012, p.96). Por sua vez, a Petrobras "útil e necessária", é evidenciada "discursivamente pela afirmação constante de seu papel essencial no desenvolvimento do país, e de como sua existência é determinante para que a economia siga uma trajetória de crescimento" (Silva, 2012, p. 97).

Outro simbolismo identificado por Silva (2012, p. 97), é o de "Petrobras 'eficiente', [...] que emerge na constante (re)afirmação como uma organização produtiva, que corresponde aos objetivos para os quais foi criada, e expresso em números e estatísticas que ajudam a realizar a 'prestação de contas' à sociedade". Petrobras "moderna e tecnológica" consiste no sexto simbolismo e está

associado à inovação (pesquisa e desenvolvimento de novas tecnologias) e aos constantes investimentos realizados em infraestrutura, seja para desenvolver as atividades da Petrobras em seus primórdios (constituição de uma infraestrutura básica), ou para afirmarse como indústria de ponta no século XXI. (Silva, 2012, p. 97)

Por fim, o último simbolismo identificado pelo autor é a Petrobras "responsável", conformado sobre a ideia de a organização se preocupar "com o bem-estar do povo brasileiro, nas ações de patrocínio a eventos culturais, no desenvolvimento de programas de responsabilidade social e de ações de respeito/preservação ao meio ambiente" (Silva, 2012, p. 97).

Expostos os simbolismos identificados por Silva (2012), reafirma-se que, neste estudo, a atenção recai sobre seus três atributos preponderantes ${ }^{6}$, sendo eles a Petrobras 1) "sinônimo de Brasil", 2) "heroica" e 3) "útil e necessária". Importa destacar que se optou por apresentar análises de quatro anúncios em que se identificou a ocorrência simultânea de pelo menos duas das três ofertas de ethos definidas para este estudo de modo a ampliar as materialidades.

Ressalta-se, novamente, que a aplicação de tópicos da Análise do Discurso (AD), especialmente a noção de ethos discursivo como elemento central de análise, objetiva evidenciar sentidos de si ofertados pela Petrobras em seus anúncios institucionais. A análise recai, fundamentalmente, sobre sequências discursivas (SD), trechos do discurso materializado nos anúncios e recortados pelo pesquisador/analista (Benetti, 2007). Com isso, procura-se lançar luzes sobre as marcas discursivas relacionadas aos atributos simbólicos associados à Petrobras.

\section{ETHOS PETROBRAS: BRASILIDADE, HEROÍSMO, UTILIDADE/NECESSIDADE}

Cumpre informar inicialmente que os anúncios são apresentados/analisados em ordem temporal de veiculação - do mais antigo para o mais recente. Nessa ordenação, o primeiro anúncio, intitulado "Aquêle abraço" (Figura 1), foi veiculado em 1969. Na parte superior da peça vê-se a imagem de dois homens se abraçando: um, de costas, veste camisa azul com a marca "Petrobrás" estampada; o outro, sorridente, visto de frente, veste camisa amarela. Abaixo da imagem, textos verbais, com destaque para a chamada do anúncio: "aquêle abraço...". 
Figura 1: Anúncio "Aquêle abraço...".

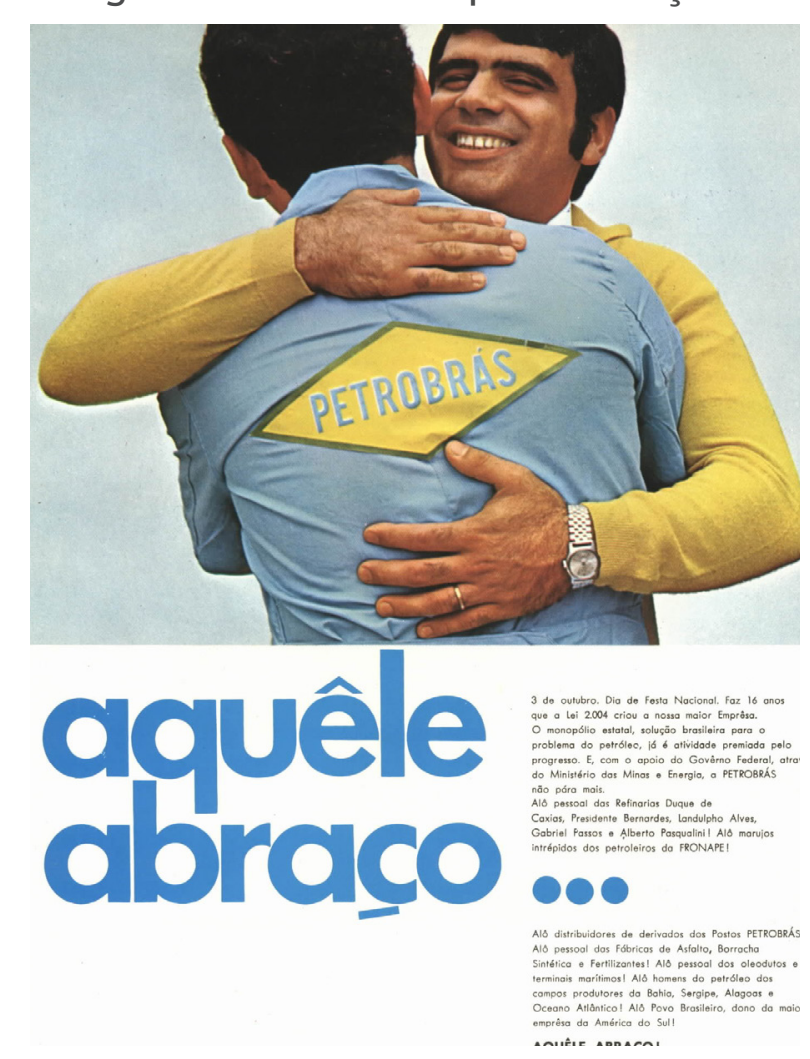

Fonte: Revista Petrobras, set./out. 1969.

A primeira SD evidencia o porquê de o 3 de outubro ser uma ocasião de festa:

3 de outubro. Dia de Festa Nacional. Faz 16 anos que a Lei 2.004 criou a nossa maior Emprêsa. 0 monopólio estatal, solução brasileira para o problema do petróleo, já é atividade premiada pelo progresso. E, com o apoio do Govêrno Federal, através do Ministério das Minas e Energia, a PETROBRÁS não pára mais. (SD1, grifos nossos)

Desse excerto, destaca-se o fato de que a Petrobras rememora a dia de sua criação (3 de outubro de 1953) como ocasião para o Brasil celebrar - festa nacional - um fato grandioso, portanto. Enuncia que, graças a uma lei, pôde ser criada a "nossa maior empresa". Assim, discursivamente, referencia um coletivo do qual ela própria faz parte: os brasileiros. A inserção do interlocutor no espaço discursivo - e a equiparação com esse locutor - é uma escolha que será repetida pela Petrobras em anúncios futuros, conforme aponta Brandão (1998). Destacam-se as expressões "festa nacional" e "solução brasileira", que ajudam a configurar o sentido de brasilidade desejado.

Outro aspecto a ser destacado na SD1 é que ao mesmo tempo que o ethos de organização sinônimo de Brasil emerge traços do ethos de organização heroica também podem ser vislumbrados. Ao articular a referência da fundação da organização ao fato de o monopólio estatal para a exploração do petróleo (a principal justificativa para a criação da Petrobras) ser "atividade premiada pelo progresso", a Petrobras afirma-se como motor para o progresso do país.

Concomitantemente, a referência a funcionários que ocupam diversas funções de trabalho na Petrobras faz emergir o ethos de organização heroica. Merece destaque a segunda SD, que contém o seguinte enunciado: "Alô pessoal das Refinarias Duque de Caxias, Presidente Bernardes, Landulpho Alves, Gabriel Passos e Alberto Pasqualini! Alô marujos intrépidos dos petroleiros da FRONAPE!' (SD2, grifo nosSo).

Aqui, os marujos dos petroleiros são qualificados como "intrépidos". Nessa direção, pode-se pensar sobre a imprevisibilidade do seu cotidiano que os coloca diante de variados desafios e até de perigos, sugerindo imagens de trabalho permeado com aventura. Essa conformação exige marujos corajosos, destemidos e obstinados, e remete à "figura do herói" (Campbell, 2011). 
Por sua vez, na SD3, o ethos de organização sinônimo de Brasil é reafirmado pela oferta de sentido de uma Petrobras grandiosa e brasileira: "Alô homens do petróleo dos campos produtores da Bahia, Sergipe, Alagoas e Oceano Atlântico! Alô Povo Brasileiro, dono da maior empresa da América do Sul!' (SD3, grifo nosso).

Ainda em referência aos seus "homens", na SD3 a Petrobras dirige-se ao seu "proprietário" - o "Povo Brasileiro" -, saudando-0. Nesse momento celebrativo, todos devem comemorar o fato de que ela é a maior empresa da América do Sul e merecem, portanto, "aquêle abraço", acionando também, de modo interdiscursivo, a canção "Aquele Abraço", composta por Gilberto Gil, em 1969.

Por sua vez, no anúncio "O Brasil começa no mar" (Figura 2), veiculado em 6 de setembro de 1972, apenas um dia antes da comemoração da independência do Brasil, os ethos de organização sinônimo de Brasil e de organização heroica emergem de maneira distinta. À época, com a ditadura militar perdurando no país já há oito anos, naquele momento sob o comando do general Emílio Garrastazu Médici, a Petrobras continuava a veicular anúncios de propaganda institucional intimamente conectados à questão nacional - é desse período o lema "Brasil: ame-o ou deixe-o" - e a peça parece evidenciar esse sentido principal.

Em termos visuais, o anúncio é composto pela imagem do mar em tons de azul/azul escuro, do céu em tons mais claros ao fundo no horizonte, e ao centro e à direita, de uma plataforma petrolífera e de um navio muito próximo a ela.

Figura 2: anúncio "O Brasil começa no mar".

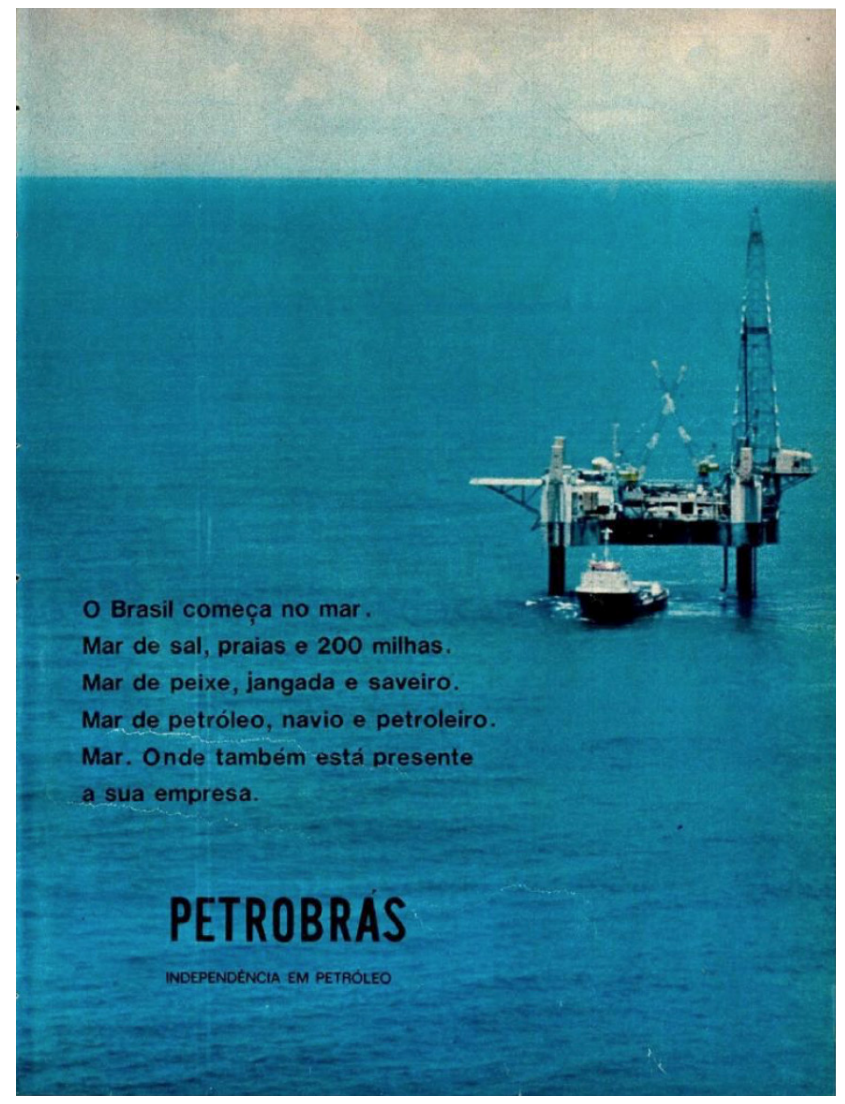

Fonte: Veja, n. 209, set. 1972.

O ethos de organização sinônimo de Brasil parece emergir logo no primeiro trecho do texto verbal: "O Brasil começa no mar. Mar de sal, praias e 200 milhas. Mar de peixe, jangada e saveiro. Mar de petróleo, navio e petroleiro. Mar. Onde também está presente a sua empresa" (SD4, grifos nossos).

Ao enunciar "O Brasil começa no mar", a Petrobras parece querer dizer da amplitude da noção de país - a ideia de Brasil. Como o país possui uma das maiores costas marítimas do planeta, e sendo o mar um dos locais-símbolo em termos imagéticos em 
diversas peças de comunicação da organização (Silva, 2012), estabelece aí a primeira parte da argumentação: o Brasil não é somente composto pelo território terrestre.

Em seguida, o trecho "Mar de peixe, jangada e saveiro..." lança luz à ideia de que o mar é um local de identificação para o povo brasileiro, uma vez que, especialmente em áreas litorâneas, a pesca é fonte de renda para parte da população, peixes e frutos do mar compõem a alimentação dos brasileiros, e o mar é povoado por embarcações como jangadas e saveiros. Essa é uma importante estratégia de identificação com o leitor, materializada no texto verbal em complemento à imagem apresentada.

É no trecho seguinte, porém, que a Petrobras se insere de forma efetiva no espaço enunciativo e na cadeia argumentativa. Com o trecho "Mar de petróleo, navio e petroleiro...", faz uma espécie de resgate da sua missão, sua razão de ser. Se o mar é de petróleo, navio e petroleiro, esse é o lugar da Petrobras, seu lugar de trabalho e de essência. Aqui também é possível pensar no ethos de organização heroica na medida que esse local é também um lugar de imensidão - a Petrobras que desbrava 0 mar infinito, cheio de mistérios. De todo modo, a Petrobras está lá, conforme se pode ler no trecho seguinte, "onde também está presente a sua empresa", em que outra oferta de sentido está presente: a da Petrobras que pertence ao interlocutorleitor, ao brasileiro.

No último excerto do texto verbal, tem-se: "Petrobrás. Independência em petróleo" (SD5). Novamente, observa-se a recuperação do sentido de brasilidade do discurso. Uma vez que se trata de propaganda realizada por ocasião da independência do Brasil, faz-se um "empréstimo de linguagem" do termo "independência", que também passa a ter um valor qualitativo, já que a Petrobras surgiu para "cuidar" do petróleo brasileiro e, assim, tornar o país independente no que tange à produção e suprimento do combustível.

0 ethos de organização útil e necessária é evidente no anúncio veiculado em 1994 (Figura 3). Por ocasião de uma série de críticas realizadas na imprensa e pela entidade sindical "Força Sindical" em relação aos problemas do monopólio da Petrobras, bem como a sua ineficiência e incapacidade de oferecer retornos na forma de benefícios à população (Silva, 2012), a Petrobras veicula o anúncio "Ter Petrobrás é tão necessário a um país que o Japão fez a Petrobrás dele", como resposta à parcela das críticas.

Figura 3: Anúncio "Ter Petrobrás é tão necessário a um país que o Japão fez a 'Petrobrás' dele".

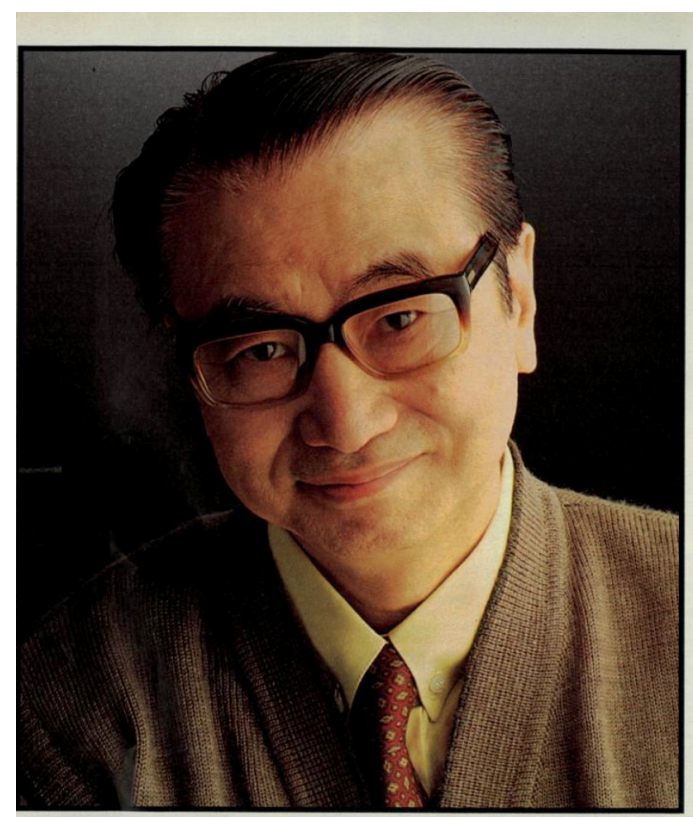

Ter Petrobrásé éta necessário a um país que o Japão lez a "petrobrás" dele.

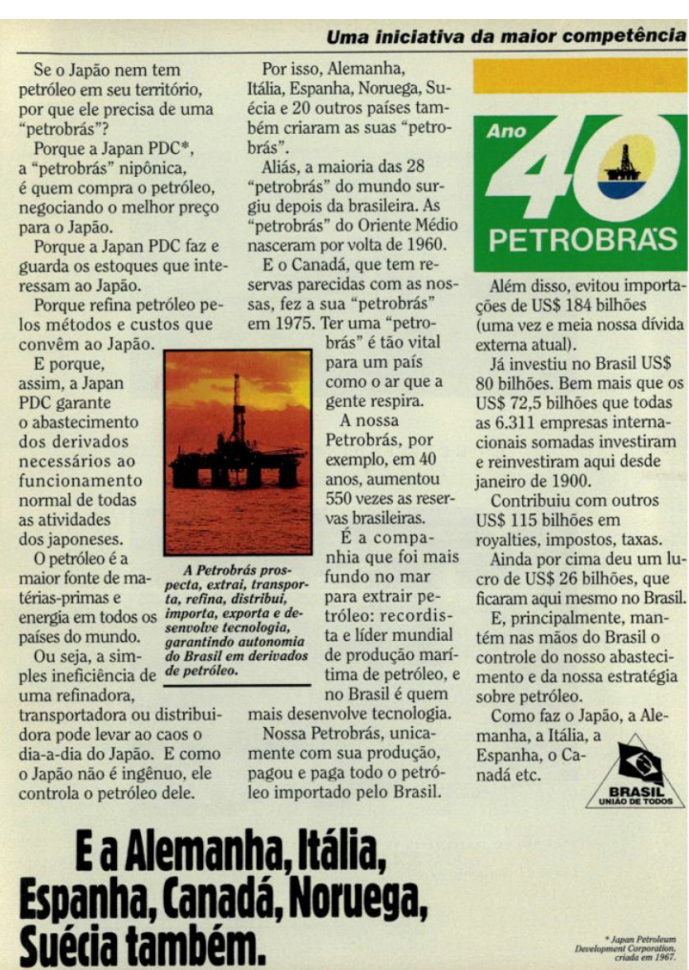

Fonte: Veja, n. 1331, mar. 1994. 
À esquerda da peça, de página dupla, está a figura de um homem de feições orientais, usando óculos, aparentando ser um executivo asiático (presumidamente japonês, considerando-se o título). Na outra página, estão dispostos: a marca comemorativa de 40 anos da Petrobras; a imagem centralizada, em tons de vermelho, de uma plataforma de petróleo; a marca de governo da época; o complemento do título; e um longo texto verbal de 19 parágrafos.

0 atributo simbólico de utilidade e necessidade da Petrobras parece evidente já a partir do título, em que se enuncia que "0 Japão fez a 'petrobras' dele". Em seguida, nos parágrafos, a Petrobras enumera algumas das razões para isso, bem como oferece mais argumentos que sustentam a oferta de sentido de utilidade/necessidade. Na SD6, tem-se:

Se o Japão nem tem petróleo em seu território, por que ele precisa de uma "petrobrás"? [...] a Japan PDC*, a "petrobrás" nipônica, é quem compra o petróleo [...] guarda os estoques... refina petróleo pelos métodos e custos que convêm ao Japão [...] a simples ineficiência de uma refinadora, transportadora ou distribuidora pode levar ao caos o dia-a-dia do Japão. E como o Japão não é ingênuo, ele controla o petróleo dele. (SD6, grifos nossos)

A estratégia argumentativa fundamenta-se em mostrar que as atividades da "Petrobras japonesa" são fundamentais no que tange ao gerenciamento do petróleo do país. E que, caso isso falhe, o caos atingirá os japoneses. Mas, como o país não é ingênuo, ele "controla" seu petróleo. Por isso, é vital que exista uma empresa que tenha por competência essas atividades. É vital que a Petrobras faça isso para o Brasil. 0 texto prossegue elencando outros países que também fizeram "a sua Petrobras".

Do box central, abaixo da imagem de uma plataforma petrolífera, destaca-se outra sequência discursiva (SD7): "A Petrobrás prospecta, extrai, transporta, refina, distribui, importa, exporta e desenvolve tecnologia, garantindo autonomia do Brasil em derivados de petróleo" (SD7, grifo nosso).

Novamente a Petrobras procura evidenciar seu valor e sua fundamental competência para gerir o petróleo nacional em todas as fases. E mais, afirma ser tão vital ao país quanto o oxigênio é para o brasileiro, conforme a SD8. Assim, dá-se a ver como basilar e legítima para o país; não deve ser questionada, portanto. "Ter uma 'petrobrás' é tão vital para um país como 0 ar que a gente respira" (SD8, grifo nosso).

O ethos de organização heroica emerge na seguinte sequência discursiva: "É a companhia que foi mais fundo no mar para extrair petróleo: recordista e líder mundial de produção marítima de petróleo, e no Brasil é quem mais desenvolve tecnologia" (SD9, grifo nosso).

Na SD9, a Petrobras enuncia a si própria como uma organização que ao enfrentar os perigos do mar, supera-os para ir além e extrair o petróleo de que o país precisa. Complementarmente, afirma ser a organização que mais desenvolve tecnologia - até para ir "mais fundo no mar" e ser "recordista e líder mundial de produção marítima". Assim, reforça a oferta de sentidos de ser relevante, seja pelo heroísmo destemido para enfrentar o mar, ir além, seja por gerir todos os processos produtivos, seja por ser ícone tecnológico. Assim, estão encadeados conceitos que gravitam em torno do valor da Petrobras como fundamental e legítima (outros países também a desejam), isto é, agente imprescindível para o desenvolvimento do país.

Por fim, o anúncio "Inspirar é aprender e ir sempre além" (Figura 4), publicado em contexto de comemoração aos 60 anos da Petrobras completados em 2013, apresenta visualmente uma mulher de pele morena, aparentando meia-idade, sorrindo e vestindo o que parece ser o uniforme e os acessórios de trabalho, com destaque para o capacete de cor amarela, os óculos e os protetores de ouvido. Ao fundo, tem-se o céu em tonalidade azul, assim como uma grande estrutura metálica complementada por um guindaste de cor vermelha, o que sugere algum tipo de plataforma ou campo de extração de petróleo ou gás. 
Figura 4: Anúncio "Inspirar é aprender e ir sempre além...".

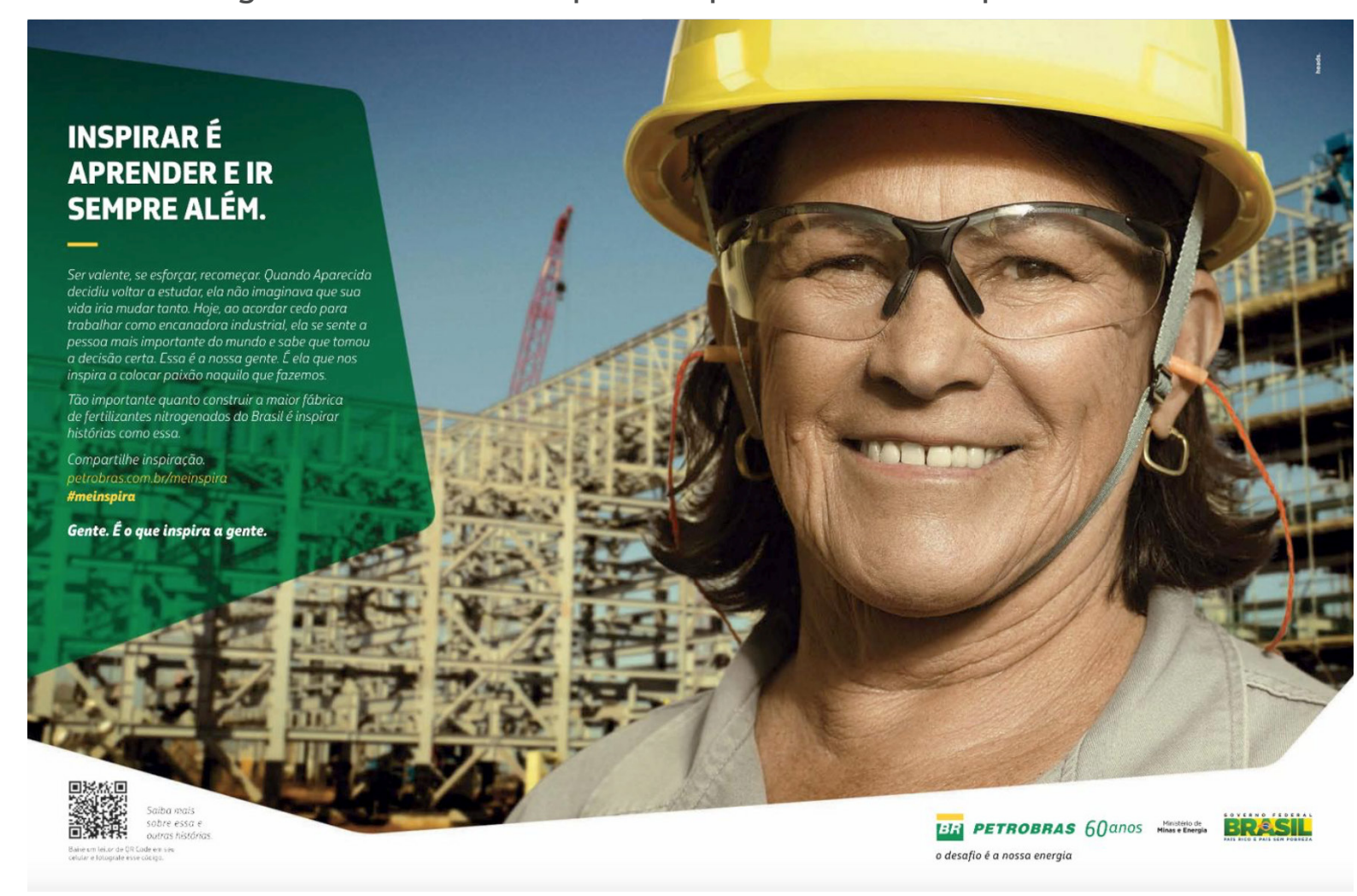

Fonte: Veja, n. 2332, jul. 2013.

No anúncio em tela, assim como nos anteriores, os ethos de organização heroica e de sinônimo de Brasil são bastante evidentes não só por conta de sua chamada principal ("Inspirar é aprender..."), mas também pela análise de excertos do texto verbal que compõem o anúncio:

Ser valente, se esforçar, recomeçar. Quando Aparecida decidiu voltar a estudar, ela não imaginava que sua vida iria mudar tanto. Hoje, ao acordar cedo para trabalhar como encanadora industrial, ela se sente a pessoa mais importante do mundo e sabe que tomou a decisão certa. (SD10, grifos nossos)

Aqui, o texto inicia com a imediata introdução das características de heroísmo da organização, através de Aparecida, que sorri e cativa o leitor: sua valentia, esforço, e capacidade de recomeço - características importantes para um herói. Vale lembrar que Campbell (2011), ao abordar a questão mítica, aponta que um dos atributos que tornam um herói mito é a sua capacidade de realização de proezas, sejam físicas (como lutar, salvar vidas etc.) ou espirituais (confrontar-se com o nível superior da vida espiritual humana e, com isso, obter uma mensagem).

Cabe ressaltar ainda outra característica heroica, a paixão, materializada na SD11: "Essa é a nossa gente. É ela que nos inspira a colocar paixão naquilo que fazemos" (SD11, grifo nosso). 0 discurso, nesse momento, parece pontuar um estado de espírito da Petrobras - de ser apaixonada e agir segundo esse sentimento - que se complementa aos outros atributos e ajuda a organização a personificar-se, isto é, quando a organização atribui a si qualidades e sentimentos humanos; não de quaisquer humanos, mas de humanos valentes.

Nesse anúncio também está presente o ethos de organização sinônimo de Brasil. Por meio do emprego da imagem da trabalhadora e pela tomada de sua história (Aparecida decidiu voltar a estudar e, assim, sua vida mudou), a Petrobras ganha um "rosto" e uma história: a trabalhadora torna-se fiadora desse processo argumentativo, e o discurso verbal, por sua vez, reforça essa estratégia em trechos destacados na SD11, como "essa é a nossa gente", "é ela que nos inspira". Assim, a Petrobras apresenta-se como valente e esforçada, da mesma maneira que o povo brasileiro é comumente representado. 


\section{CONSIDERAÇÕES FINAIS}

A partir das análises empreendidas, é possível revelar algumas das estratégias discursivas que a Petrobras emprega em sua comunicação organizacional de maneira a atualizar e (re)afirmar os atributos simbólicos identificados e associados à organização. Nessas estratégias, observa-se um processo em que o oferecimento de sentidos e imagens de si é sustentado/ potencializado por meio do ethos discursivo.

Os atributos simbólicos de organização "sinônimo de Brasil", "heroica" e "útil e necessária" refletem, dessa forma, a oferta de imagens de si calcadas em características e aspectos de sua identidade organizacional, acionadas sempre que é necessário combater ou neutralizar crises ou, então, em momentos em que a demanda é por legitimação. Desse modo, a Petrobras busca exibir uma identidade organizacional solidificada, ao mesmo tempo que esses elementos se tornam material qualificador de sua imagem-conceito.

Os atributos simbólicos fornecem um repertório temático - conceitos, ideias e semânticas acionadas em variadas configurações semióticas - que ajuda a Petrobras a construir-se, discursivamente, de forma perene no tempo. Com isso, o público é sempre relembrado que a organização é um símbolo de brasilidade, tecnologia, inovação, responsabilidade, eficiência (Silva, 2012).

Para a sua comunicação organizacional, os atributos oferecem a sustentação necessária para que estratégias e ações sejam colocadas em práticas e, por meio de seus processos, façam com que esses conceitos circulem entre os públicos. Sendo constantemente (re)atualizados, os atributos contribuem para que a Petrobras permaneça ocupando um lugar no imaginário do país, blindando-a (ou camuflando-a) em momentos de crises como escândalos de corrupção, ou (re)afirmando-a como ícone do desenvolvimento e progresso.

\section{REFERÊNCIAS}

BALDISSERA, Rudimar. Imagem-conceito: anterior à comunicação, um lugar de significação. 2004. Tese (Doutorado em Comunicação Social) - Pontifícia Universidade Católica do Rio Grande do Sul, Porto Alegre, 2004.

Comunicação organizacional: uma reflexão possível a partir do paradigma da complexidade. In: OLIVEIRA, Ivone Lourdes de; SOARES, Ana Thereza Nogueira. (Orgs.). Interfaces e tendências da comunicação no contexto das organizações. São Paulo: Difusão, 2008. p. 149-177.

Comunicação organizacional na perspectiva da complexidade. Revista Organicom, São Paulo, ano 6, n. 10/11, p. 115120, 2009a. Edição especial.

A teoria da complexidade e novas perspectivas para os estudos de comunicação organizacional. In: KUNSCH, Margarida M. K. (Org). Comunicação organizacional: histórico, fundamentos e processos. São Paulo: Saraiva, 2009b. v. 1, p. 135-164.

. A complexidade dos processos comunicacionais e interação nas organizações. In: MARCHIORI, Marlene. (Org). Faces da cultura e da comunicação organizacional. São Caetano do Sul: Difusão Editora, 2010. v. 2, p. 199-213.

BALDISSERA, Rudimar; SILVA, Magno Vieira da. Organizações comunicadas e ethos discursivo: imagens de si ofertadas em sites institucionais. In: MARCHIORI, Marlene; OLIVEIRA, Ivone de Lourdes (Orgs.). Redes sociais, comunicação, organizações. São Caetano do Sul: Difusão Editora, 2012. p.167-184. 
BENETTI, Marcia. Análise do discurso em jornalismo: estudo de vozes e sentidos. In: BENETTI, Marcia; LAGO, Cláudia (Org.). Metodologia de pesquisa em jornalismo. Petrópolis: Vozes, 2007. p. 107-122.

BRANDÃO, Helena Hathsue Nagamine. Subjetividade, argumentação, polifonia: a propaganda da Petrobras. São Paulo: Ed. Unesp, 1998.

CAMPBELL, Joseph. O poder do mito. 28. ed. São Paulo: Palas Athena, 2011.

MAINGUENEAU, Dominique. Cenas da enunciação. São Paulo: Parábola Editorial, 2008.

Ethos, cenografia, incorporação. In: AMOSSY, Ruth. (Org.). Imagens de si no discurso: a construção do ethos. 2. ed. São Paulo: Contexto, 2011. p. 69-92.

MORIN, Edgar. Introdução ao pensamento complexo. 3. ed. Lisboa: Instituto Piaget, 2001.

OLIVEIRA, Ivone de Lourdes; PAULA, Carine Fonseca Caetano de. Comunicação no contexto das organizações: produtora ou organizadora de sentidos? In: OLIVEIRA, Ivone Lourdes de; SOARES, Ana Thereza Nogueira. (Orgs.). Interfaces e tendências da comunicação no contexto das organizações. São Paulo: Difusão, 2008. p. 91-108.

SILVA, Magno Vieira da. Mito, organizações e comunicação: o caso da Petrobras. 2012. 172 f. Dissertação (Mestrado em Comunicação e Informação) - Faculdade de Biblioteconomia e Comunicação, Universidade Federal do Rio Grande do Sul, Porto Alegre, 2012.

Texto recebido em: 09.04.2017 e aprovado em 03.09.2017. 